Welcome to the 26th volume of the International Journal of Technology Assessment in Health Care (IJTAHC). The editorial office has moved from the Institute of Health Economics in Alberta, Canada, to the National Institute for Health and Welfare (THL) in Finland and its Finnish Office for Health Technology Assessment (FINOHTA). It is exciting and challenging to take the helm of this journal. Knowing its history and cherishing its strengths, I wish to keep the HTA community engaged in making and using the journal as its scientific sounding board and its flagship.

Some changes are here already: The new cover design is accompanied by a novel grouping of the articles. Another change, invisible to readers but helpful to authors and referees, will be the web-based submission and editorial system to be introduced this year-technologies change in publishing as well as in health care. All changes rest on the groundwork of yesteryears, so it is proper to recall what this journal is and has been.

As the new Chief Editor of IJTAHC, I am deeply indebted to my predecessor, Professor Egon Jonsson, who skillfully navigated this Journal from a fledgling paper to an established publication. A quarter of a century might set a record among medical journal editors! During his term of service, he also strongly supported the growth of the scientific society, now Health Technology Assessment International (HTAi). Over the years, Egon has hand picked an able group of experts from the ranks of the society and journal contributors into the Editorial Board, a priceless inheritance for the next editor.

\section{The Society and Its Journal}

Developing side by side, HTAi and its journal have provided a multidisciplinary home base for health care scholars, professionals, decision makers, and providers of care and technology. Together they have asked prudent questions about technologies and their role in health care, developed methods for answering these questions thoroughly and transparently, and participated in policy discussions at home and in the world. Presentations at HTAi meetings often mature to publications in the journal.

From the ten pages of the first Xeroxed newsletter, the Sorcerer's Apprentice, to the 300-page History of HTA supplement, many things have changed but some remain: Egon Jonsson and David Banta were active contributors to the newsletter and now edited the magnum opus (1). Terminology, "a constant source of confusion and miscommunication" for the Apprentice, still keeps us discussing. From the editorial board of 1985, Jeremiah Barondess, David, and Duncan Neuhauser remain on the crew.

In addition to studying the history issue carefully, I have acquainted myself with the Sorcerer's Apprentice, or "A newsletter dedicated to international communication and cooperation concerning the assessment of medical technology and health policymaking" at the HTAi website. Among reports, network news, and calls for information, the satires were tagged clearly so readers would not be led to believe the journal was seriously suggesting permanent hospitalization for all.

\section{Wider Audience, New Tools}

The fresh cover design by Wayne Pollack spans health care from scientific methods to patients. The selection of images parallels the journal's traditionally broad interpretation of technology and also reflects my wish to attract more research relevant to low and middle income countries. The colors now match the HTAi logo on the cover, too.

Articles are grouped according to three major themes: Assessments, Policies, and Methods. Three is a simplification, surely, and studies may straddle two categories; the aim is to help you in finding topics of interest. This issue features methodologists discussing the use of registers, databases, and quality-of-life measurements. Technology assessments have addressed psychoanalysis, prevention, vaccinations, and screening. Policy analysts take up coverage with evidence development and HTA principles. Please continue the discussion: letters are welcomed, just keep them short and to the point. For satires, cartoons, and poetry I promise a separate section should these cross the reviewers' threshold for quality.

During 2010, the editorial system will be transferred to the web for speed and security. An organized review process will provide a better overview of the many manuscripts at various steps of evaluation, and easier communication 
with authors. The expectations are similar to what people in general wish technologies will do for them: help in doing things well. Managing manuscript versions, affiliation forms, and copyrights will become simpler for all.

Along with technical changes, the journal will follow the recommendation of the International Committee of Medical Journal Editors (2) and starts asking the authors to disclose their potential conflicts of interest using a digital form, available at www.icmje.org. For information used as an input to policy decisions, such transparency is essential.

The quality of this journal is up to you, dear authors, reviewers, and readers. As the editor, I aim at providing a forum for well-researched and clearly argued studies on relevant topics. Health care abounds with good questionsanswer them with good methods and tell us what you did. Argue, reflect, and innovate. Health care needs you.
Professor Marjukka Mäkelä, $\mathrm{MD}, \mathrm{PhD}, \mathrm{MSc}$

Editor-in-Chief, International Journal of Technology

Assessment in Health Care

Director of FINOHTA (Finnish Office for Health

Technology Assessment) at THL (National Institute for Health and Welfare)

P.O.Box 30, 00271 Helsinki, Finland

Tel.:+358 206107290 , Fax: +358 206107278

E-mail: marjukka.makela@thl.fi

\section{REFERENCES}

1. Jonsson E, Banta D, eds. Int J Technol Assess Health Care: History of HTA. 2009;25:Suppl 1.

2. Drazen JM, van der Weyden M, Sahni P, Rosenberg J, Marusic A, et al. Uniform format for disclosure of competing interests in ICMJE journal. N Engl J Med. 2009; Oct 13. [Epub ahead of print]. 